\title{
KEPATUHAN PESERTA DIDIK MAHASISWA DALAM MELAKSANAKAN SOP PENGOPERASIAN ALAT ELEKTROKARDIOGRAM (EKG)
}

\author{
Santi Zulmedia ${ }^{1)}$ \\ ${ }^{1}$ Prodi D3 Keperawatan, jln Indragiri Padang Harapan, Kota Bengkulu \\ *Email: santizulmedia@gmail.com
}

\begin{abstract}
Abstrak
Pemasangan EKG merupakan prosedur invasif dan merupakan tindakan yang sering dilakukan di rumah sakit (RS), namun hal ini berisiko tinggi terjadinya kesalahan diagnosa (error diagnosed) akibat dari kesalahan. Tindakan pemasangan Elektrokardiogram (EKG) akan berkualitas apabila dalam pelaksanaannya selalu patuh pada Standar Prosedur Operasional (SOP). Alat yang telah ditetapkan demi terciptanya pelayanan kesehatan yang bermutu. Penelitian ini bertujuan untuk mengetahui bagaimana kepatuhan mahasiswa dalam melaksanakan SOP pemasangan Elektrokardiogram (EKG) di laboratorium keperawatan Fakultas Matematika dan Ilmu Pengetahuan Alam Universitas Bengkulu. Penelitian ini merupakan penelitian kualitatif dengan rancangan studi kasus yang hasilnya disajikan secara deskriptif. Populasi yakni seluruh mahasiswa perawat prodi D3 keperawatan yang sudah melakukan tindakan Elektrokardiogram (EKG) dengan jumlah sampel 57 responden. Data dikumpulkan dengan cara observasi lembar check list Standar Oprasional Prosedure (SOP) Pemasangan Elektrokardiogram (EKG) dan wawancara mendalam. Hasil observasi menunjukkan bahwa seluruh perawat patuh (78\%) dalam melaksanakan SOP pengoperasian Alat EKG. Hasil wawancara mendalam menunjukkan bahwa komitmen terhadap kepatuhan mahasiswa perawat sudah terwujud dengan baik dalam hal pelaksanaan SOP pengoperasian Alat EKG. Hal ini dapat disebabkan sudah dilakukan sosialisasi dan evaluasi SOP pemasangan EKG. Disimpulkan bahwa seluruh mahasiswa perawat patuh dalam melaksanakan SOP pengoperasian alat EKG di laboratorium keperawatan FMIPA UNIB.
\end{abstract}

Kata kunci: kepatuhan mahasiswa perawat, Standar Prosedur Operasional (SOP) pengoperasian alat elektrokardiogram ( $\mathrm{EKG)}$

\begin{abstract}
ECG installation is an invasive procedure and is a procedure that is often performed in hospitals, but it has a high risk of error diagnosis due to errors. The act of installing an Electrocardiogram (ECG) will be of high quality if in its implementation it is always obedient to the Standard Operating Procedures (SOP) for tools that have been established for the creation of quality health services. This study aims to determine how students' compliance in carrying out the SOP for the installation of an Electrocardiogram (EKG) in the nursing laboratory of the Faculty of Mathematics and Natural Sciences, Bengkulu University. This research is a qualitative research with a case study design whose results are presented descriptively. The population is all nursing students of the D3 nursing study program who have performed Electrocardiogram (EKG) with a sample of 57 respondents. Data were collected by observing the checklist of Standard Operating Procedures (SOP) for Electrocardiogram (ECG) installation and in-depth interviews. The results of the observations showed that all nurses were obedient (78\%) in carrying out the SOP for the operation of the ECG device. The results of in-depth interviews show that the commitment to student nursing compliance has been well realized in terms of implementing the SOP for the operation of the ECG Device. This could be due to the socialization and evaluation of the SOP for EKG installation. It was concluded that all nursing students were obedient in carrying out the SOP for the operation of the ECG device in the nursing laboratory of FMIPA UNIB.

Keywords: nursing student compliance, Standard Operating Procedures for operating the device
\end{abstract}

\section{PENDAHULUAN}

Laboratorium pendidikan Prodi D3 Keperawatan merupakan slah satu unit penunjang akademik pada lembaga pendidikan, berupa ruangan tertutup dan terbuka, yang bersifat permanen atau bergerak, dikelola secara sistematis dengan menggunakan peralatan dan bahan tertentu, dalam melaksanakan proses pendidikan, penelitian dan pengabdian kepada masyarakat. Peran laboratorium sangat penting dalam hal mendorong optimalisasi proses pembelajaran, sebagai pendidikan vokasi yang berfokus pada pelayanan kesehatan kepada masyarakat, laboratorium merupakan tempat yang tepat bagi mahasiswa dalam melatih keterampilan sebelum mahasiswa terjun kemasyarakat. Mahasiswa dituntut terampil dalam melaksanakan praktik baik mandiri maupun secara tim. Di laboratorium mahasiswa akan dilatih melalui sistem praktikum utama (dibimbing oleh dosen) dan praktikum secara mandiri (mahasiswa belajar mandiri dibawah pengawasan dosen) di laboratorium dengan menggunakan alat peraga panthom/ manikin yang ada di laboratorium dan manusia (teman mahasiswa yang dijadikan pasien). 
Pengelolaan laboratorium yang baik diharapkan dapat terciptanya laboratorium keperawatan yang kompeten dan berdaya saing, sehingga menghasilkan tanaga keperawatan yang unggul dan memenuhi standar kompetensi yang dibutuhkan oleh lapangan kerja.

Sehubungan dengan itu diperlukan suatu upaya untuk memenuhi capaian kompetensi tersebut maka institusi perlu menyiapkan suatu standar yang akan diguanakan sebagai acuan dalam suatu kegiatan pelayanan di laboratrorium. Salah satu kegiatan pelayanan di laboratorium adalah pengelolaan pengoperasian peralatan. Peralatan yang ada di laboratorium merupakan alat penunjang bagi mahasiswa dalam melakukan pembelajaran praktikum. Agar alat yang digunakan oleh mahasiswa dalam kegiatan praktikum dapat digunakan dalam jangka waktu yang lama maka di perlukan adanya Standar Operasioanal Prosedur (SOP) dalam melakukan pengoperasian peralatan tersebut. Menurut Laksmi (2008), Standar Operasional Prosedur merupakan dokumen yang menjelaskan terperinci mengenai suatu prosedur yang dilakukan secara kronologis untuk menyelesaikan suatu pekerjaan yang bertujuan untuk memperoleh hasil kerja yang paling efektif dari para pekerja dengan biaya yang serendahrendahnya (efisien). Format SOP biasanya terdiri dari diantaranya seperti manfaat, tanggal dibuat atau direvisi, metode penulisan prosedur, kemudian dilengkapi dengan bagan flowchart di bagian akhir. Dalam melaksanakan SOP diperlukan suatu kepatuhan oleh pemakainya, salah satunya seperti mahasiswa. Mahasiswa diwajibkan mematuhi Standar Operasional Prosedur (SOP) dalam mengoperasikan suatu peralatan. Melakukan pengoperasian alat dari awal sampai akhir sesuai dengan prosedur diharapkan agar mendapatkan nilai ukur yang akurat dan valid. Setiap alat yang ada di laboratorium apapun bentuk dan jenisnya harus mempunyai sebuah panduan dalam pengoperasiannya (SOP) yang bertujuan untuk meminimalisir terjadinya kerusakan alat, ataupun kecelakan kerja saat mengoperasikan alat. Selain itu dengan adanya SOP diharapkan alat yang digunakan memiliki masa operasional yang panjang (awet).

Standar Prosedur Operasional (SOP) pengoperasian alat Elektrokardiogram merupakan salah satu Standar Prosedur Operasional (SOP) yang ada di laboratorium. Standar Prosedur Operasional (SOP) Elektrokardiogram menjelaskan cara pengoperasian alat tersebut dari awal penggunaan hingga akhir penggunaan alat. Diperlukan kecermatan dan ketelitian dalam mengoperasikan alat tersebut dikarenakan Elektrokardiogram (EKG) merupakan alat sensitif yang merekam aktivitas kelistrikan jantung dalam waktu tertentu. Kesalahan dalam mengoperasikan alat EKG akan berakibat fatal, karena dapat mengakibatkan kesalahan diagnosis penyakit pada pasien, sehingga dapat menyebabkan pula kesalahan dalam pemberian terapi pengobatan pada pasien. Untuk menghindari hal tersebut maka diperlukannnya kepatuhan mahasiswa terhadap SOP yang ada dalam mengoperasikan alat Elektrokardiogram (EKG).

\section{METODE PENELITIAN}

Penelitian ini merupakan rancangan studi kasus (case study) kualitatif yang hasilnya disajikan secara deskriptif. Penelitian ini dilakukan untuk mengetahui bagaimana kepatuhan mahasiswa perawat dalam melaksanakan (SOP) pengoperasian alat Elektrokardiogram (EKG) di Laboratorium Keperawatan FMIPA UNIB. Pada penelitian ini populasinya adalah semua peserta didik mahasiswa yang melakukan tindakan pengoperasaian Elektrokardiogram (EKG).

Populasi dalam penelitian 57 tindakan dalam pengoperasaian pemasangan Elektrokardiogram (EKG). yang dilakukan oleh mahasiswa yang melakukan tindakan pada waktu melakukan laboratorium mandiri dan dan saat ujian OSCA. Sampel adalah sebagian dari keseluruhan objek yang diteliti dan dianggap mewakili seluruh objek populasi (Nursalam, 2003). Sampel penelitian ini adalah total sampling yaitu seluruh populasi yang menjadi kriteria sampel yaitu mahasiswa yang melakukan praktikum tindakan EKG sebanyak 57 mahasiswa, pada kegiatan laboratorium mandiri dan Ujian OSCA. Indikator, alat ukur, skala data, skor kategori Variabel Definisi Operasional Indikator Alat ukur Skala data Skor dan kategori Kejadian eror rekaman hasil rekaman yang grafik naik turun, grafik yang tebal, grafik yang terputus 1 Tidak Eror : 0. Kepatuhan Peserta didik dalam mengoperasikan alat Elektrokardiogram (EKG) observasi Nominal Patuh : 1 Tidak patuh : 0 SOP pengoperasaian EKG sesuai dengan SOP Laboratorium yaitu teknik menghidupkan alat yang baik, teknik pengoperasian alat Elektrokardiogram $(\mathrm{EKG})$ dan teknik mematikan alat yang baik dengan kriteria patuh skor nilai $\geq 75$ tidak patuh $\leq 75$.

Pengumpulan data ini, hasil rekaman Elektrokardiogram (EKG) dinyatakan eror apabila hasil lembar rekaman EKG terdapat grafik yang naik turun, grafik rekaman yang garisnya tebal, grafik rekaman yang terputus putus. Mahasiswa dinyatakan patuh apabila dalam melaksanakan pengoperasian 
Elektrokardiogram (EKG sesuai dengan SOP dan dinyatakan hasil rekaman tidak Error apabila hasil lembar rekaman EKG tidak terdapat grafik yang naik turun, grafik rekaman yang garisnya tidak tebal, grafik rekaman yang tidak terputus putus. Untuk variabel independen menggunakan lembar observasi SOP Pengoperasian alat Elektrokardiogram (EKG) Untuk variabel dependen dilakukan observasi/pengamatan secara langsung. Sumber data didapat dari data primer. Data primer adalah data yang didapat dari tangan pertama, yamg diperoleh langsung dari subyek penelitian dengan menggunakan alat pengukur atau alat pengambil data, langsung pada subyek sebagai sumber informasi yang dicari (Sugiyono, 2008). Pengumpulan data primer dalam penelitian ini adalah lembar observasi Pengoperasian Elektrokardiogram (EKG dan lembar observasi pengoperasaian Elektrokardiogram (EKG sesuai SOP atau tidak).

Data yang telah terkumpul kemudian diolah. Tujuan dari tindakan ini adalah menyederhanakan seluruh data yang terkumpul dan menyajikannya dalam bentuk susunan yang rapi. Dalam proses pengolahan data langkahlangkah yang akan ditempuh adalah sebagai berikut:

1. Editing Setelah semua data terkumpul, kemudian dilakukan editing data yang telah terkumpul dengan menilai apakah data yang telah terkumpul sudah cukup relevan untuk diolah atau diproses lebih lanjut. Semua data bisa diisi dengan lengkap.

2. Coding Memberi kode pada setiap variabel digunakan untuk mempermudah peneliti dalam melakukan tabulasi dan analisa data. Hal ini penting dilakukan karena alat yang digunakan untuk analisa data adalah komputer melalui program SPSS yang memerlukan kode tersebut.

Pada penelitian ini untuk variabel dependen yaitu kejadian eror hasil rekaman EKG:

a. Error terdapat terlihat grafik yang naik turun, garis tebal dan putus diberi kode 1 .

b. Tidak error tidak terdapat grafik yang naik turun, tebal dan putus putus diberi kode 0 .

Variabel independen kepatuhan perawat dalam melaksanakan Standar Oprasional Prosedur (SOP) pengoperasian peralatan Elektrokardiogram (EKG) jika responden menjawab Patuh nilai : 1 dan jika jawaban responden tidak patuh : 0 Patuh jika mendapat skor nilai $\geq 75$, Tidak patuh, jika mendapat skor nilai $<75$. Analisis data yang bertujuan untuk menganalisis hubungan antar variabel pada penelitian ini yaitu observasi kepatuhan mahasiswa dalam melakukan pengoperasian Elektrokardiogram (EKG). Sedangkan data yang terkumpul disajikan dalam bentuk tabulasi silang antara variabel dependen dengan variabel independen selanjutnya diuji dengan bantuan komputer dengan program Statistical Product And Service Solution (SPSS). Penelitian ini menggunakan uji statistik Chi Square. Didapatkan hasil tolak ukur kepatuhan mahasiswa dalam melaksanakan Standar Operasional Prosedur (SOP) pengoperasaian peralatan Elektrokardiogram (EKG).

\section{HASIL DAN PEMBAHASAN}

Kepatuhan mahasiswa perawat terhadap SOP pengoperasian alat elektrokardiogram( EKG) di laboratorium Keperawatan FMIPA Universitas Bengkulu, di peroleh 57 orang kategori patuh (78\%), adapun deskripsinya disajikan pada Gambar 1:

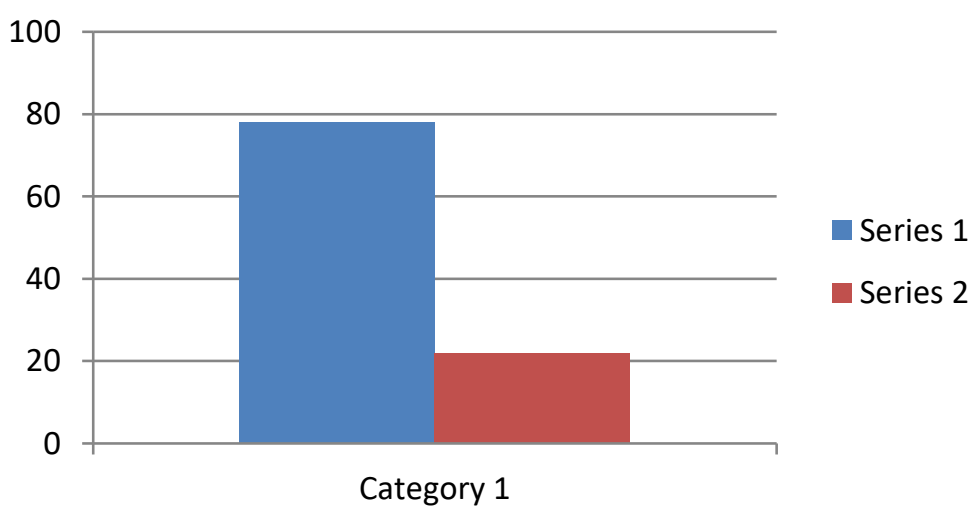

Gambar 1. Deskripsi Mahasiswa Perawat Berdasarkan Kepatuhan dalam Melaksanakan SOP Pengoperasian Alat EKG di laboratorium Keperawatan FMIPA UNIB 
Berdasarkan hasil observasi pengoperasian EKG, diperoleh bahwa sebanyak $78 \%$ responden atau mahasiswa perawat melaksanakan pengoperasian alat EKG sesuai dengan SOP yang berlaku. SOP pengoperasian alat EKG yang berlaku di laboratorium keperawatan FMIPA UNIB pada tahun 2010. Berdasarkan kebijakan dari unit laboratorium, SOP tersebut dapat dievaluasi kapan saja tergantung situasi dan kondisi tetapi maksimal setiap 2 tahun sekali. Hal tersebut tentu saja tidak dilaksanakan dengan baik karena SOP pengoperasian EKG yang ada di laboratorium keperawatan sampai penelitian dilakukan masih merupakan SOP yang diterbitkan pada tahun 2020.

Dari data yang didapat dijelaskan bahwa 57 mahasiswa prodi D3 Keprawatan yang melakukan tindakan pengoperasian EKG diperoleh kepatuhan mahasiswa dalam pengoperasian EKG adalah berjumlah 45 orang dengan persentasi $78 \%$ dan mahasiswa yang tidak patuh terhadap SOP pengoperasaian alat EKG yaitu berjumlah 12 orang dengan persentase $22 \%$.

SOP yang ada dilaboratorium dilaksanakan oleh semua mahasiswa yang akan menggunakan semua peralatan yang ada di laboratorium, termasuk SOP pengoperasian EKG. Sebelunya melakukan SOP pengoperasian alat mahasiswa terlebih dahulu mendapatkan informasi tentang SOP alat yang terdiri dari tujuan, ruang lingkup alat, defenisi alat, Rujukan pengoperasian alat, prinsip kerja alat dan cara kerja alat. Carpenito (2000), menyebutkan bahwa dalam hal pemahaman tentang instruksi, tentunya tidak seorang pun mematuhi instruksi jika ia salah paham tentang instruksi yang diberikan padanya. Terkadang hal ini disebabkan oleh kurangnya sosialisasi tentang instruksi tersebut, penggunaan istilah-istilah yang tidak umum dalam instruksi dan memberikan banyak instruksi yang harus diingat oleh penerima instruksi.

Dalam hal pemahaman instruksi tentunya hal tersebut tidak lepas dari tingkat pendidikan. Menurut Carpenito (2000), pendidikan dapat meningkatkan kepatuhan, sepanjang bahwa pendidikan tersebut merupakan pendidikan yang aktif yang diperoleh secara mandiri. Semakin tinggi tingkat pendidikan akan semakin tinggi tingkat keinginan untuk memanfaatkan pengetahuan dan keterampilan. Menurut Notoatmodjo (2003), salah satu faktor yang berpengaruh terhadap tingkat pengetahuan adalah pendidikan, sehingga apabila sebagian besar pendidikan perawat sudah cukup tinggi maka tingkat pengetahuan sebagian besar dalam kategori baik merupakan suatu kewajaran saja. Berdasarkan hasil wawancara dengan mahasiswa perawatan yang melaksankan praktik keperawatan didapatkan bahwa sebenarnya salah satu praktik keperawatan yang penting seperti pengoperasian EKG masih terdapat beberapa hal yang perlu dibenahi. Untuk komitmen tentang kepatuhan melaksanakan SOP pengoperasian EKG seluruh mahasiswa perawat memiliki komitmen yang tinggi. Berdasarkan observasi pelaksanaan proses pengoperasian EKG menurut SOP yang telah di laboratorium keperawatan, mahasiswa sudah memahami dan hapal SOP pengoperasian EKG walaupun ada beberapa mahasiswa yang tidak hapal secara keseluruhan sehingga tidak semua poin yang terdapat di dalam SOP dilakukan dengan baik. Komitmen memang penting dilakukan karena menurut Cialdini dan Martin (2004), dalam prinsip komitmen atau konsistensi, ketika seseorang telah mengikatkan diri pada suatu posisi atau tindakan, seseorang tersebut akan lebih mudah memenuhi permintaan akan suatu hal yang konsisten dengan posisi atau tindakan sebelumnya dalam hal ini adalah kepatuhan terhadap SOP pengoperasian EKG. Namun pada penelitian ini didapatkan bahwa komitmen mahasiswa perawat tinggi sehingga hal tersebut secara tidak langsung menyebabkan kepatuhan terhadap SOP yang berlaku. Komitmen erat kaitannya dengan tanggung jawab. Tanggung jawab merupakan sesuatu yang harus atau wajib dilakukan dan dikerjakan. Dengan adanya rasa tanggung jawab maka akan dapat meningkatkan kinerja terutama dalam hal ini tindakan pengoperasian alat EKG. Sebagian perawat mengambil tanggung jawab penuh untuk melaksanakanpengoperasian alat EKG dengan baik meskipun sebagian tanggung jawab tersebut ada pada atasan. Hal ini sesuai dengan teori Milgram (1963), yaitu aouto-mous state dimana seseorang mengambil tanggung jawab penuh atas apa yang dilakukannya. Pemberian instruksi atau perintah oleh atasan terkadang menjadi beban bagi pelaksana perintah tersebut sehingga perintah tersebut ada yang tidak dilaksanakan. Suatu perintah atau instruksi mungkin tetap dilaksanakan sekedarnya sehingga tidak sesuai dengan apa yang diperintahkan.

Kepatuhan mahasiswa perawat dalam penerapan standar pelayanan keperawatan dan SOP sebagai salah satu ukuran keberhasilan pelayanan laboratorium dan merupakan sasaran penting dalam manajemen laboratorium keperawatan. Penerapan SOP pelayanan laboratorium pada prinsipnya adalah bagian dari kinerja dari Pranata Paboratorium Pendidikan (PLP) dalam bekerja sesuai tugasnya dalam organisasi, dan biasanya berkaitan dengan kepatuhan. Kepatuhan mahasiswa perawat adalah perilaku perawat sebagai seorang yang profesional terhadap suatu anjuran, prosedur atau peraturan yang harus dilakukan atau ditaati. 


\section{KESIMPULAN DAN SARAN}

Berdasarkan hasil penelitian dan analisis data dan pembahasan tentang kepatuhan mahasiswa terhadap SOP pengoperasian alat Elektrokardiogram (EKG) prodi D3 Keperawatan FMIPA UNIB yang telah diuraikan di atas maka diambil beberapa kesimpulan sebagai berikut : Mahasiswa perawat prodi D3 Keperawatan sudah mempunya komitmen bahwa pentingnya mematuhi SOP Pengoperasian Alat Elektrokardiogram(EKG), walaupun ada beberapa orang yang masih belum mematuhinya. Penerapan SOP pengoperasian alat EKG baru berlaku pada tahun 2020, namun masih ada mahasiswa yang belum patuh terhadap SOP penggunaan alat. Dengan kepatuhan mahasiswa dalam pengoperasian alat akan memberikan dampak yang baik bagi usia alat dan masa pakai alat.

\section{DAFTAR PUSTAKA}

Andares. Analisa Hubungan Karakteristik Perawat dan Tingkat Kepatuhan Perawat dalam Pelaksanaan Protap Pemasangan Infus di Rumah Sakit Badrul Aini Medan, Tesis. Medan: Program Pasca Sarjana, Minat Magister Kesehatan Universitas Sumatera Utara. 2009.

Carpenito L.J. Diagnosa Keperawatan; Aplikasi pada Praktik Klinis, 6th edn. Jakarta: EGC. 2000.

Cialdini R, Martin. The Science of Compliance. United States of America: Arizona State. 2004.

Notoatmodjo S. Pendidikan dan Perilaku Kesehatan. Jakarta: Rineka Cipta. 2003.

Mangkunegara. Evaluasi Kinerja SDM. Bandung: Refika Aditama. 2006.

Milgram, Stanley. Behavioral study of obedience. The Journal of abnormal and social psychology, 1963, 67.4: 371.

Syarif A. Faktor-faktor yang Berhubungan dengan Kepatuhan Perawat dalam Melaksanakan Standar Operasional Prosedur Pemasangan Infus di Ruang Merak RSUP Dr.Kariadi Semarang. Tesis. Yogyakarta: Program Pasca Sarjana, Minat Magister Rumah Sakit, Universitas Gajah Mada. 2012.

Kusumadewi, S. Hardjajani, T. \& Priyatama, AN. Hubungan antara Dukungan Sosial Peer Group dan Kontrol Diri dengan Kepatuhan terhadap Peraturan pada Remaja Putri di Pondok Modern Islam Assalam Sukoharjo. Jurnal Ilmiah Psikologi Candrajiwa, 2012; 1 (2):1-10.

Widyaningtyas KS. Analisis Faktor-faktor yangMempengaruhi Kepatuhan Perawat dalamPendokumentasian Asuhan Keperawatan.Tesis. Semarang: Program Pasca Sarjana, Minat Magister Keperawatan, Universitas Diponegoro. 2010. 